\title{
Comparative visible-light driven selective oxidation to aldehydes of phenylmethanol (benzyl alcohol) and 4-pyridinylmethanol (4-pyridinecarbinol) on $\mathrm{N}-\mathrm{TiO}_{2}$ and some commercial $\mathrm{TiO}_{2}$ samples
}

\author{
Luca Samiolo $^{2} \cdot$ Rossano Amadelli $^{2} \cdot$ Andrea Maldotti $^{1} \cdot$ Alessandra Molinari $^{1}$ D \\ Received: 1 September 2021 / Accepted: 8 November 2021 / Published online: 21 November 2021 \\ (c) The Author(s), under exclusive licence to European Photochemistry Association, European Society for Photobiology 2021
}

\begin{abstract}
Visible light $(\lambda>420 \mathrm{~nm})$ selective photooxidation of phenylmethanol and 4-pyridinylmethanol in $\mathrm{CH}_{3} \mathrm{CN}$ to the corresponding aldehydes on $\mathrm{N}-\mathrm{TiO}_{2}$ is compared with homemade undoped $\mathrm{TiO}_{2}\left(\mathrm{U}-\mathrm{TiO}_{2}\right)$ and commercial undoped anatase specimens (such as PC105, PC500). Significant differences observed between $\mathrm{N}^{-\mathrm{TiO}_{2}}$ and undoped $\mathrm{TiO}_{2}$ are neither directly related to the surface area nor to the adsorbed amount of alcohol in the dark by surface area unit. FTIR and EPR spectroscopies are used to study the surface of $\mathrm{TiO}_{2}$ samples and to deeply understand the phenomena intervening in the visible-light photocatalytic activation of the doped vs the undoped oxides. In particular, it is shown that on $\mathrm{N}^{-\mathrm{TiO}_{2}}$ (and also on undoped PC105) strong Lewis acid sites (LAS) exist. The favorable role of LAS on the photocatalytic activity is illustrated by the higher photooxidation of 4-pyridinylmethanol vs phenylmethanol over $\mathrm{N}^{-\mathrm{TiO}_{2}}$ and $\mathrm{PC} 105$ in contrast to the other undoped samples, whose visible light sensitivity originates from a charge transfer between the alcohol and the solid. EPR spectra of $\mathrm{N}^{-T i O}{ }_{2}$ point out the presence of paramagnetic centers related to nitrogen that disappear when the photocatalyst is irradiated with visible light in the presence of alcohol, which starts its oxidative process. On the basis of presented results, we propose that doping with $\mathrm{N}$ introduces new intraband gap states that not only contribute to LAS and adsorption of alcohol but also are directly involved in the photochemical process occurring under visible light irradiation.
\end{abstract}

\section{Graphical abstract}

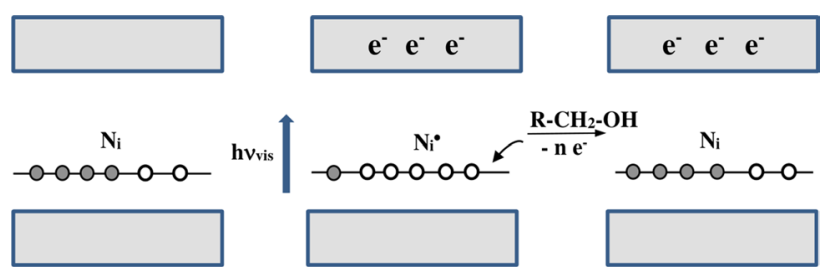

Keywords $\mathrm{N}$-doped $\mathrm{TiO}_{2} \cdot$ Benzyl alcohol $\cdot$ IR spectroscopy $\cdot$ Visible light $\cdot$ Lewis acid site

\section{Introduction}

Alessandra Molinari

alessandra.molinari@unife.it

1 Dipartimento di Scienze Chimiche, Farmaceutiche ed Agrarie, Università di Ferrara, Via L. Borsari 46, 44121 Ferrara, Italy

2 c/o Dipartimento di Scienze Chimiche, Farmaceutiche ed Agrarie, ISOF CNR, UoS di Ferrara, Università di Ferrara, Via L. Borsari 46, 44121 Ferrara, Italy
A wide array of issues concerning photocatalysis by $\mathrm{TiO}_{2}$ have been addressed, most notably its poor absorption of visible light. Accordingly, efforts to extend absorption into the visible spectral range have been important and research in this field has made significant progress (see for example Ref. [1]) while keeping in mind that high visible-light absorption alone does not necessarily imply a high photocatalytic activity. Several approaches have been explored including: (i) dye 
sensitization [2], (ii) doping [3-11], and (iii) surface complexes formation $[10,12]$. Some good results concerning the photocatalytic activity by visible light have been obtained with metal ion doping [3, 4]. Unsurprisingly, it was found that this activity depends on the preparation method: for example, in the case of Co-doped $\mathrm{TiO}_{2}$, surface interstitial doping was effective in the visible-light photocatalytic degradation of organic substrates, whereas lattice substitution was not [13].

Doping by non-metals, which was a relatively later strategy, has been a flourishing research field. Especially for nitrogen-doped $\mathrm{TiO}_{2}\left(\mathrm{~N}-\mathrm{TiO}_{2}\right)$, the number of publications and reviews has grown extensively [5-11].

Aside from the domain of photocatalysis, $\mathrm{N}$-doped oxides have been successfully used for application in gate dielectric in field-effect transistors [14]. Concerning the location of the dopant, it is agreed that nitrogen can be incorporated in interstitial positions $\left(\mathrm{N}_{\mathrm{i}}\right)$ and/or substitute for oxygen $\left(\mathrm{N}_{\mathrm{s}}\right)$ but the debate on which of the two doping modes is more photochemically effective appears inconclusive.

Visible-light photocatalysis over $\mathrm{N}_{-1 i O}$ [15-17] includes cases with significant activity [18] and others with no activity at all, also depending on the preparation method and on the target chemical compounds.

Quite a few studies have addressed the issue of selectivity, a key topic in fine chemicals production through photocatalysis and conventional catalysis [19]. In particular, the selective catalytic oxidation of alcohols to carbonyl compounds is one of the most important chemical transformations in organic syntheses also on an industrial scale [20]. In general, a selective reaction requires a surface arrangement that limits the reactivity of an adsorbed organic intermediate, so that desorption of partially oxidized species is faster than further oxidation.

Each step of the (photo)catalytic process must be optimized, and alcohol oxidation is, by the way, a typical reaction used to probe surface characteristics, such as, for example, vacancies and defects. The vast literature available on alcohols (photo)reactivity underlines that catalyst defects play a paramount role [21].

The photooxidation of phenylmethanol (benzyl alcohol; $\mathrm{PhCH}_{2} \mathrm{OH}$ ) to phenylmethanal (benzaldehyde; $\mathrm{PhCHO}$ ) has often been investigated as a test reaction. In addition, benzaldehyde is widely used in a number of industrial processes as building block. In the research domain of surface electronics modification by adsorbed species and its effects on visible-light photocatalysis, a review containing key references focusing on the selective oxidation of benzyl alcohol derivatives has been published [10]. Both experimental data and theoretical calculations have indicated the appearance of new occupied and unoccupied states upon adsorption as a result of the hybridization of the $\mathrm{PhCH}_{2} \mathrm{OH}$ molecular orbitals with the $\mathrm{O}_{2 \mathrm{p}}$ atomic orbitals of $\mathrm{TiO}_{2}$. Charge transfer
(CT) complexes are thus formed, giving rise to visible-light response [10].

In a study on the selective conversion of benzyl and cinnamyl alcohols to the corresponding aldehydes [22], it was observed that on a homemade $\mathrm{N}_{-} \mathrm{TiO}_{2}$ the photocatalytic process was totally selective. Conversely, $\mathrm{Li}$ et al. [23] reported that the photocatalytic activity of $\mathrm{N}-\mathrm{TiO}_{2}$ for benzyl alcohols oxidation was very poor. This discrepancy furtherly confirmed the effect of the preparation methods on the visiblelight photocatalytic activity of these materials.

In this broad context, the present work examines the visible-light photooxidation of $\mathrm{PhCH}_{2} \mathrm{OH}$ to $\mathrm{PhCHO}$ on $\mathrm{N}-\mathrm{TiO}_{2}$ in comparison with that obtained on homemade undoped $\mathrm{TiO}_{2}\left(\mathrm{U}_{-} \mathrm{TiO}_{2}\right)$ and some commercial undoped anatase specimens, such as PC105 and PC500. The focus was photocatalytic process selectivity while also seeking additional elements that could increase our understanding of the phenomena intervening in the visible-light photocatalytic activity of the doped vs the undoped $\mathrm{TiO}_{2}$. In particular, the importance of Lewis acid sites (LAS) that can favour adsorption of alcohols behaving as Lewis bases is highlighted here. In fact, the role of LAS, related to surface coordinative unsaturation, has been often stressed as an important property affecting surface reactivity at metal oxides and continues to be an interesting topic of research [24-26]. In particular, their role in photocatalytic reactions, including the oxidation of benzyl alcohols, has recently been discussed [27, 28].

To our knowledge, Lewis surface acidity of $\mathrm{N}-\mathrm{TiO}_{2}$ prepared by the wet method, has not been examined before. The comparative investigation on $\mathrm{N}-\mathrm{TiO}_{2}$ and on several $\mathrm{TiO}_{2}$ samples reported here benefits not only from FTIR studies of acetonitrile or pyridine adsorption, but also from the results of 4-pyridinylmethanol $\left(\mathrm{PyCH}_{2} \mathrm{OH}\right)$ selective photooxidation to the corresponding aldehyde (PyCHO), compared to that of $\mathrm{PhCH}_{2} \mathrm{OH}$. In addition, using room temperature EPR spectroscopy, we highlight differences in the mechanism of selective $\mathrm{PhCH}_{2} \mathrm{OH}$ photooxidation on $\mathrm{N}-\mathrm{TiO}_{2}$, in contrast with unmodified commercial anatase samples, which only involve a photochemical CT process induced by adsorption.

\section{Experimental}

\subsection{Materials}

All chemicals, viz. acetonitrile ( $<0.005 \%$ water), anhydrous $\mathrm{PhCH}_{2} \mathrm{OH}, \mathrm{PyCH}_{2} \mathrm{OH}, \mathrm{PhCHO}$ and $\mathrm{PyCHO}$ were obtained from Sigma-Aldrich and used as received.

Homemade nitrogen-doped and undoped $\mathrm{TiO}_{2}$ were obtained following a previously reported procedure [22], which involves precipitation from $\mathrm{TiOSO}_{4}$ with $\mathrm{NH}_{4} \mathrm{OH}$ $\left(\mathrm{N}-\mathrm{TiO}_{2}\right)$ or $\mathrm{NaOH}\left(\mathrm{U}-\mathrm{TiO}_{2}\right)$. The $\mathrm{TiO}_{2}$ (anatase) samples 
PC500 and PC105 were Cristal Millenium products (the latter obtained from the first by a sintering process) and have previously been characterized (see, for example, Ref. [29]). Following evacuation at $120{ }^{\circ} \mathrm{C}$, the $\mathrm{TiO}_{2}$ samples were stored in a dry atmosphere under argon.

\subsection{Equipment}

In adsorption and photocatalytic experiments, the chemical analyses were carried out on a HP6890 gas chromatograph (Agilent Technologies) equipped with a flame ionization detector using an HP-WAX capillary column for $\mathrm{PhCH}_{2} \mathrm{OH}$ and a DB624 capillary column for $\mathrm{PyCH}_{2} \mathrm{OH}$. For quantitative analysis, we constructed calibration curves using the pure alcohols or the corresponding aldehydes at different concentrations. In addition, the conversion of $\mathrm{PyCH}_{2} \mathrm{OH}$ to $\mathrm{PyCHO}$ was followed also by UV visible spectroscopy (Jasco V570). The irradiation source was a $\mathrm{Hg}$ medium pressure lamp (Helios Italquartz) equipped with cutoff filters. Monochromatic filters were used for the calculation of quantum yields.

A FTIR Bruker Vertex 70 spectrometer equipped with a CricketTM accessory was used to record diffuse reflectance FTIR (DRIFT) spectra at $1 \mathrm{~cm}^{-1}$ resolution. All DRIFT measurements were performed at room temperature and results are reported as absorbance spectra.

EPR experiments were carried out at room temperature using a X band Bruker 220 SE spectrometer. Flat quartz cells were employed for powder suspensions. MW Frequency $9.4 \mathrm{GHz}$, MW power $63 \mathrm{~mW}$, Mod. Amplitude $100 \mathrm{kHz}$. The instrument was calibrated with 1,1-diphenyl2-picrylhydrazyl (DPPH; $g$ value: 2.0036) as reference. In some cases, the samples placed in the instrument cavity were directly exposed to the light emitted by the aforementioned $\mathrm{Hg}$ medium pressure lamp equipped with a $\lambda>420 \mathrm{~nm}$ cutoff filter.

DR-UV-Vis spectra were collected with a Jasco V-570 spectrophotometer equipped with a diffuse reflectance accessory and using $\mathrm{BaSO}_{4}$ as reference.

\subsection{Methods}

The amount of adsorbed alcohol $\left(q_{\text {ads }}\right)$ was obtained by suspending the photocatalyst $\left(4 \mathrm{~g} \mathrm{~L}^{-1}\right)$ in a $\mathrm{CH}_{3} \mathrm{CN}$ solution of the alcohol $\left(1 \times 10^{-3} \mathrm{M}\right)$ and stirring this suspension in the dark for $1 \mathrm{~h}$. The results reported are the average of at least five repeated experiments. In this case as well as in all other experiments, final results were accepted with an error lower than 5\%.

All DRIFT spectra were recorded against air on powders that were mixed in fixed proportion with $\mathrm{KBr}$. For the spectra of modified $\mathrm{TiO}_{2}$, the dry powder of the samples were exposed to vapours of either acetonitrile or pyridine in a controlled stream of dry argon followed by evacuation at $100{ }^{\circ} \mathrm{C}$. In each case a baseline was recorded using the same, unmodified $\mathrm{TiO}_{2}$; the instrument allows an automatic background correction. Reproducibility was checked by comparing spectra recorded in the same conditions.

Photocatalytic experiments were conducted with suspensions composed as described just above. A small Pyrex semi-cylindrical reactor with a flat window was used. The suspension was magnetically stirred, oxygenated by maintaining the reactor under pure $\mathrm{O}_{2}$ at $1 \mathrm{~atm}$, and irradiated $(1 \mathrm{~h})$ with the aforementioned medium pressure $\mathrm{Hg}$ lamp equipped with cutoff or monochromatic filters. No oxidation products were obtained when the experiments were run in the dark or when the oxygenated alcohol solutions were irradiated in the absence of a photocatalyst.

Evaluation of quantum yields (Eq. 1) was done with monochromatic irradiation, using a fixed amount $\left(4 \mathrm{~g} \mathrm{~L}^{-1}\right)$ of photocatalyst and the measured initial rates of aldehyde formation that were normalized to the surface areas of the photocatalyst employed [22]:

$\varphi=\frac{\text { rateofRCHOformation }\left(\mu \mathrm{molm}^{-2} s^{-1}\right)}{\text { photonirradiance }\left(\mu \mathrm{molm}^{-2} s^{-1}\right)}$

The incident light intensity $\left(\mu \mathrm{W} \mathrm{cm}{ }^{-2}\right)$ was measured with a power meter Newport Mod. 1918-C. The photon irradiance refers to the net light intensity measured across the cell in the absence and in the presence of the suspension; in all cases the amount of the suspension ensured complete absorption of the incident light.

\section{Results and discussion}

The photocatalytic activity is examined for visible light irradiation only, since, as mentioned earlier [22], in the UV-region undoped and $\mathrm{N}$-doped $\mathrm{TiO}_{2}$ behave similarly, i.e., a relatively high reactivity but a low selectivity toward aldehyde formation.

Section 3.1 concerns the dark adsorption and selective photocatalytic oxidation of $\mathrm{PhCH}_{2} \mathrm{OH}$. Section 3.2 focuses on the role of LAS in the adsorption process, because, as anticipated in the Introduction, the adsorption of alcohols on metal oxides is often related to LAS. Section 3.3 continues the analysis of the role of LAS by reporting results on the dark adsorption and the photocatalytic oxidation of $\mathrm{PyCH}_{2} \mathrm{OH}$, which is a more basic substrate than $\mathrm{PhCH}_{2} \mathrm{OH}$. Finally, Sect. 3.4 reports room-temperature EPR measurements regarding $\mathrm{N}-\mathrm{TiO}_{2}$ on the presence of nitrogen impurities and defects associated with LAS. 


\subsection{Photocatalytic oxidation of phenylmethanol $\left(\mathrm{PhCH}_{2} \mathrm{OH}\right)$}

Table 1 reports the adsorbed amounts in the dark per surface area unit $\left(q_{\mathrm{ads}}\right)$ and the visible-light selective conversion of the alcohol to the corresponding aldehyde $(\mathrm{PhCHO} /$ $\mathrm{PhCH}_{2} \mathrm{OH}$ ratio) on laboratory prepared doped $\left(\mathrm{N}-\mathrm{TiO}_{2}\right)$ and undoped $\left(\mathrm{U}_{-} \mathrm{TiO}_{2}\right)$ catalysts as well as on some anatase commercial samples; for completeness surface areas and average particle sizes are also listed.

It appears that under prolonged irradiation $(1 \mathrm{~h})$ the formation of $\mathrm{PhCHO}$ on commercial catalysts roughly increases with increasing surface area and hence, possibly, with the number of $\mathrm{OH}$ groups [30]. One can also identify a correlation between $q_{\mathrm{ads}}$ and PhCHO formation. Most importantly, this table shows the substantial effect of nitrogen doping on this oxidation under visible-light irradiation. This effect appears especially evident when comparing $\mathrm{N}-\mathrm{TiO}_{2}$ with $\mathrm{U}-\mathrm{TiO}_{2}$ and $\mathrm{PC} 105$ whose surface areas and $q_{\text {ads }}$ values are close.

The high conversion $\left(\mathrm{PhCHO} / \mathrm{PhCH}_{2} \mathrm{OH}=0.98\right)$ obtained with $\mathrm{N}^{-\mathrm{TiO}_{2}}$ is in accordance with the visible light absorption of this sample beyond $400 \mathrm{~nm}$ (Fig. 1S, curve 1). Figure 1S reports also the UV-visible spectrum of PC500 (curve 2): as expected, when $\mathrm{PhCH}_{2} \mathrm{OH}$ is present, surface adsorption on $\mathrm{TiO}_{2}$ occurs (Fig. $1 \mathrm{~S}$, curve 3 ), giving rise to a ligand-to-metal charge transfer band (LMCT) in the visible spectral region [10]. A comparison between curves 1 and 3 shows that LMCT absorption was weaker than that observed with $\mathrm{N}-\mathrm{TiO}_{2}$ by a factor of $4-5$.

The activity of a catalyst, in general, can be affected by factors related to the extension of the surface area and/

Table 1 Adsorbed amount and visible light photocatalytic conversion of benzyl alcohol $\left(\mathrm{PhCH}_{2} \mathrm{OH}\right)$ to benzaldehyde $(\mathrm{PhCHO})$ on nitrogen-doped $\mathrm{TiO}_{2}\left(\mathrm{~N}-\mathrm{TiO}_{2}\right)$, undoped home-made $\mathrm{TiO}_{2}\left(\mathrm{U}-\mathrm{TiO}_{2}\right)$ and on commercial $\mathrm{TiO}_{2}$ specimen

\begin{tabular}{|c|c|c|c|c|}
\hline $\mathrm{TiO}_{2}$ sample & $\begin{array}{l}\text { BET area } \\
\left(\mathrm{m}^{2} \mathrm{~g}^{-1}\right)^{\mathrm{a}}\end{array}$ & $\begin{array}{l}\text { Average } \\
\text { particle size } \\
(\mathrm{nm})\end{array}$ & $\begin{array}{l}\mathrm{PhCH}_{2} \mathrm{OH} \\
\text { adsorbed }\left(q_{\text {ads }}\right. \\
\left.\mu \mathrm{mol} \mathrm{m})^{-2}\right)^{\mathrm{b}}\end{array}$ & $\begin{array}{l}\mathrm{PhCHO} / \\
\mathrm{PhCH}_{2} \mathrm{OH}^{\mathrm{b}}\end{array}$ \\
\hline $\mathrm{N}^{-\mathrm{TiO}_{2}}$ & 80 & 22 & 0.14 & 0.98 \\
\hline $\mathrm{U}^{-\mathrm{TiO}_{2}}$ & 75 & 20 & 0.11 & 0.13 \\
\hline PC105 & $85-95$ & 20 & 0.10 & 0.19 \\
\hline PC500 & 317 & 8 & 0.16 & 0.28 \\
\hline
\end{tabular}

${ }^{\mathrm{a}}$ This paper and Ref. [29]

${ }^{\mathrm{b}}$ Comparative experiments were carried out suspending a fixed amount of catalyst $\left(4 \mathrm{~g} \mathrm{~L}^{-1}\right)$ in a $\mathrm{CH}_{3} \mathrm{CN}$ solution containing $\mathrm{PhCH}_{2} \mathrm{OH}\left(1 \times 10^{-3} \mathrm{M}\right)$ followed by visible light irradiation $(\lambda>420 \mathrm{~nm})$. Adsorption in the dark and the effects of illumination were evaluated after $1 \mathrm{~h}$ equilibration. Quantitative analyses were carried out by gas chromatography (see Experimental section). Reported results are the average of several repeated experiments. Errors never exceeded $\pm 5 \%$ or by the presence of active sites [31]. In general, it is not always a question of the number of sites but also of their nature. The full identification of active sites on surfaces is a challenging task, and the following text includes results regarding the nature of active sites that could be involved in our probe photocatalytic process.

\subsection{DRIFT spectra of adsorbed $\mathrm{CH}_{3} \mathrm{CN}$ and pyridine}

\subsection{1 $\mathrm{CH}_{3} \mathrm{CN}$}

In the present study, acetonitrile was used as the solvent; calculations have shown that it forms a strongly oriented layer at the $\mathrm{TiO}_{2}$ interphase [32]. In the case of $\mathrm{N}-\mathrm{TiO}_{2}$, some of us have pointed out an important role in photoelectrocatalysis of the interaction of $\mathrm{CH}_{3} \mathrm{CN}$ with the surface [22].

It is also noteworthy that acetonitrile is a medium strength base that has frequently been employed to assess the presence of acidic surface sites of oxides, including $\mathrm{TiO}_{2}$. Its interaction with $\mathrm{Br} ø$ nsted $\left(-\mathrm{OH} \ldots \mathrm{N} \equiv \mathrm{C}-\mathrm{CH}_{3}\right)$ and with Lewis acid $\left(-\mathrm{Ti} \ldots \mathrm{N} \equiv \mathrm{C}-\mathrm{CH}_{3}\right.$ ) surface sites has been conveniently investigated by FTIR spectroscopy [33-39]. Thus we employed this technique with the aim to gain a first insight into the characteristics of $\mathrm{N}-\mathrm{TiO}_{2}$ compared with undoped $\mathrm{U}_{-} \mathrm{TiO}_{2}$ and with commercial $\mathrm{TiO}_{2}$.

Figure $2 \mathrm{~S}$ displays the $\mathrm{OH}$ stretching region before and after contact of $\mathrm{N}^{-\mathrm{TiO}_{2}}$ with $\mathrm{CH}_{3} \mathrm{CN}$. The spectrum obtained in the absence of $\mathrm{CH}_{3} \mathrm{CN}$ shows narrow bands in the $3600-3800 \mathrm{~cm}^{-1}$ region which are assigned to differently coordinated surface $\mathrm{OH}$ groups [35]. As observed before [36], exposure to $\mathrm{CH}_{3} \mathrm{CN}$ caused a pronounced intensity decrease of the bands at 3665 and $3695 \mathrm{~cm}^{-1}$ attributed to Brønsted acidity.

More interestingly, Fig. 1 shows bands at lower wavenumbers with both PC500 and $\mathrm{U}_{-} \mathrm{TiO}_{2}$ (part A) and with $\mathrm{N}-\mathrm{TiO}_{2}$ (part B) after the contact with $\mathrm{CH}_{3} \mathrm{CN}$. In Fig. 1A, the bands at 2320 and $2292 \mathrm{~cm}^{-1}$ match the reported values for the $\mathrm{C} \equiv \mathrm{N}$ stretching of $\mathrm{CH}_{3} \mathrm{CN}$ adsorbed on Lewis acid sites (LAS) of anatase via the nitrogen lone pair [38-40]. In the same spectral region, the broad band at $2350 \mathrm{~cm}^{-1}$ observed for $\mathrm{N}^{-T i O}$ (Fig. 1B) is suggested to correspond to the $\mathrm{Ti} \ldots . . \mathrm{NCCH}_{3}$ interaction, already observed for the undoped oxide, but shifted to higher wavenumbers, indicating the existence of stronger LAS [40].

Among the commercial $\mathrm{TiO}_{2}$ samples, $\mathrm{PC} 105$ represents a particular case: in addition to bands at 2320 and $2292 \mathrm{~cm}^{-1}$ as for PC500 (Fig. 1A), it shows a band at $2340 \mathrm{~cm}^{-1}$ and a pronounced shoulder at $2323 \mathrm{~cm}^{-1}$ (Fig. 2). These higher wavenumber signals can be ascribed to the presence of LAS in the commercial PC105 too. 


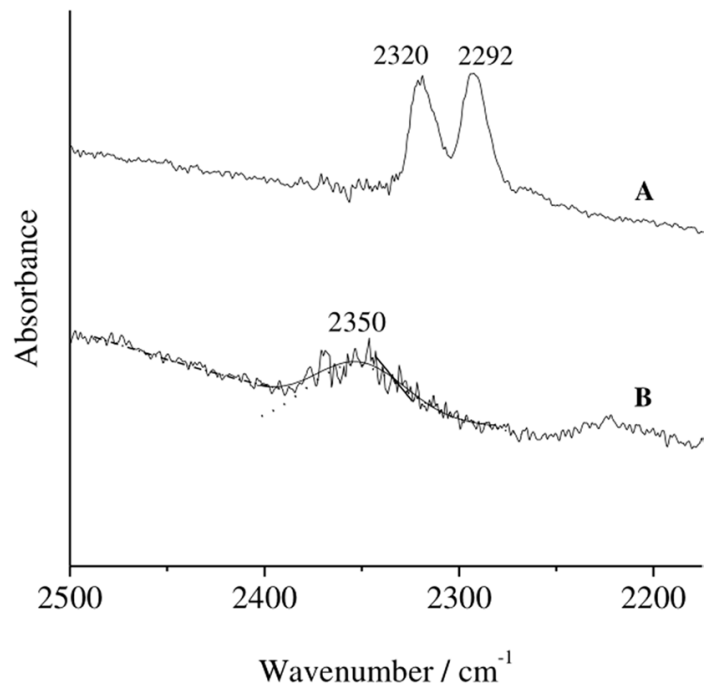

Fig. 1 DRIFT spectra in the $\mathrm{CN}$ stretching region for $\mathrm{CH}_{3} \mathrm{CN}$ adsorbed on PC500 and $\mathrm{U}_{-} \mathrm{TiO}_{2}(\mathbf{A})$ and on $\mathrm{N}-\mathrm{TiO}_{2}(\mathbf{B})$

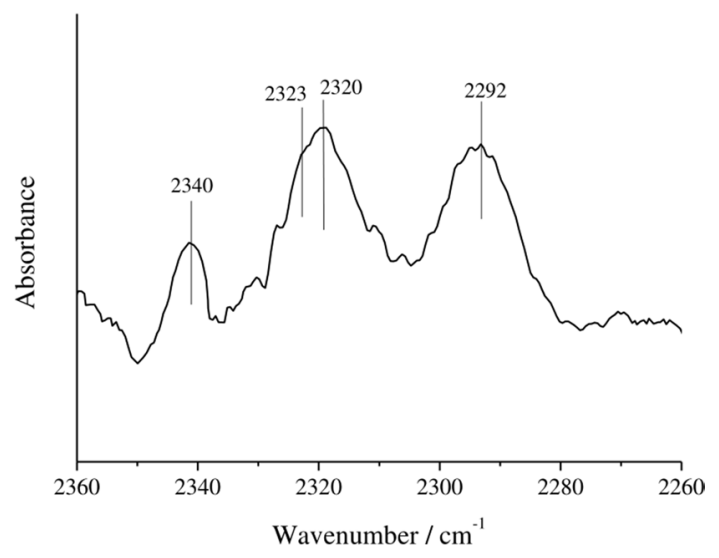

Fig. 2 DRIFT spectra in the $\mathrm{CN}$ stretching region for $\mathrm{CH}_{3} \mathrm{CN}$ adsorbed on PC105

\subsubsection{Pyridine}

To confirm the presence of Lewis/Brønsted acid sites we used pyridine, which has been widely employed as an IR probe to reveal the presence of acid sites on surfaces [41], including $\mathrm{TiO}_{2}$ [42]. FTIR spectra for pyridine adsorbed on different $\mathrm{TiO}_{2}$ samples are given in Fig. 3. It is seen that the presence of LAS on $\mathrm{N}-T i O_{2}$ is important (trace 1). On the contrary, PC500 shows a comparatively low surface Lewis acidity (trace 3); a very similar behavior is observable for $\mathrm{U}^{-\mathrm{TiO}_{2}}$ (data not shown). Interestingly, the behaviour of $\mathrm{PC} 105$ is again intermediate (trace $\mathbf{2}$ ).

It is sometimes stated that DRIFT measurements can reveal trends although they do not allow precise acid site quantification [43]. In principle, however, the knowledge of integrated areas of the band at $1445 \mathrm{~cm}^{-1}$ (Fig. 3) and of

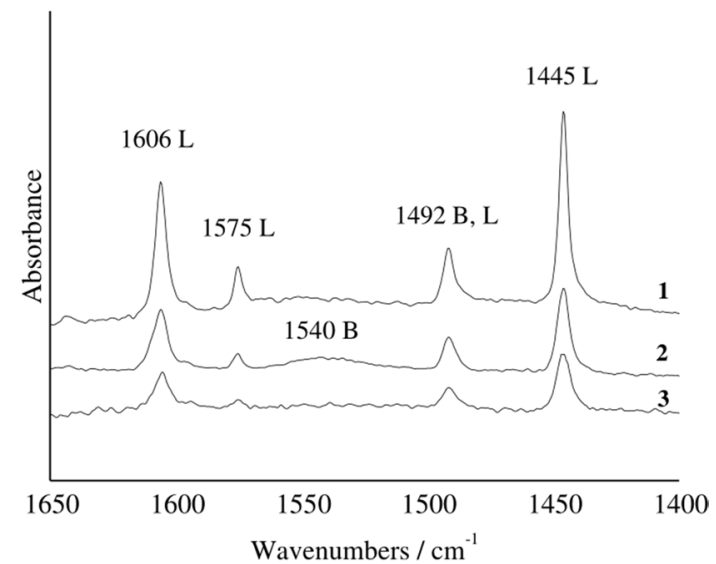

Fig. 3 DRIFT spectra of adsorbed pyridine on different $\mathrm{TiO}_{2}$ samples: 1 N-TiO 2 , 2 PC105, 3 PC500. (L stands for Lewis and B for Brønsted)

the surface concentration of the probe $\left(\mu \mathrm{mol} \mathrm{m}{ }^{-2}\right)$ (Fig. 3S) allows an estimation of the number of LAS [44]. Since a comparison seems to be more rigorous for samples having similar areas and particle sizes [45], our focus was restricted to $\mathrm{N}^{-\mathrm{TiO}_{2}}$ and PC105 among commercial samples (Table 1); the results (Supplementary Information) showed that the proportion of LAS on $\mathrm{N}-T i O_{2}$ is higher than that of PC105 by a factor of about 2 .

Several reasons can be mentioned for the higher density and strength of LAS of PC105 than of PC500 (Fig. 3S). Possibly, during the sintering of PC500 to prepare PC105 some planes could be preferentially exposed. Changes in LAS due to differences in the geometric arrangement of the surface $\mathrm{O}^{2-}$ anions could hence occur, which seemingly indicates that the chemical behaviour of both Lewis acid and Lewis base sites depends on the surface structure. In this regard, an important recent FTIR study by Mino et al. [46] shows, for the particular case of PC105, the contribution of facets and Ti centres with high coordinative unsaturation (and high Lewis acidity).

Alcohols are weak Lewis bases and, in principle, their adsorption is expected to be stronger at LAS. From a general point of view, a possible pathway of alcohol adsorption would be dissociation at defects [47]:

$\mathrm{ROH}+\mathrm{V}_{\mathrm{o}}+\mathrm{O}_{\mathrm{b}} \rightarrow \mathrm{RO}_{\mathrm{ads}}+\mathrm{HO}_{\mathrm{b}}$

$\mathrm{ROH}+\mathrm{Ti}_{5 \mathrm{c}}+\mathrm{O}_{\mathrm{b}} \rightarrow \mathrm{ROTi}+\mathrm{HO}_{\mathrm{b}}$

where $\mathrm{V}_{\mathrm{o}}$ is an oxygen vacancy, $\mathrm{O}_{\mathrm{b}}$ is a bridge oxygen and $\mathrm{Ti}_{5 \mathrm{c}}$ are coordinatively unsaturated $\mathrm{Ti}$ cations. Because of their unsaturated coordination, both $\mathrm{V}_{\mathrm{o}}$ and $\mathrm{Ti}_{5 \mathrm{c}}$ are Lewis acidic sites [21, 47].

We note, however, that the difference in LAS between PC105 and PC500 (vide supra) did not affect the dark 
adsorption and the photocatalytic oxidation of $\mathrm{PhCH}_{2} \mathrm{OH}$ (Table 1), as one would expect from reactions 2 and 3 . The reason may be that $\mathrm{PC} 105$, as the other undoped $\mathrm{TiO}_{2}$ samples, likely follows the mechanism proposed by Higashimoto [10], whereby benzyl alcohol molecules first interact with surface $\mathrm{OH}$ groups and then rearrange to form a surface complex [21, 48].

Recent calculations reveal that the first step is the determining one, since the intermolecular dehydrogenation is a fast step, possessing very low or almost zero barrier [49]. We can speculate that despite clear evidence of Lewis acid sites on PC105, these are not sufficiently strong to change the adsorption mechanism of a weak base as benzyl alcohol.

Concerning $\mathrm{N}_{-} \mathrm{TiO}_{2}$, the comparison with and without adsorbed $\mathrm{PhCH}_{2} \mathrm{OH}$, gives a difference FTIR spectrum that shows negative bands between 3100 and $3700 \mathrm{~cm}^{-1}$ (Fig. 4S), confirming that this alcohol interacts with the surface $\mathrm{OH}$ groups as reported in earlier works. It is noteworthy that this difference spectrum also contains a new positive band at $\sim 1100 \mathrm{~cm}^{-1}$ that is generally attributed to alcohols adsorbed in the form of alcoholate [33, 50]. For $\mathrm{PhCH}_{2} \mathrm{OH}$ this band is clearly visible only in the case of $\mathrm{N}^{-\mathrm{TiO}_{2}}$ and one is tempted to attribute the high photoactivity of this catalyst to a more favourable alcoholate formation due to the presence of stronger LAS on this catalyst.

To get more insights into the factors governing the mechanisms, in the following we will consider the effect of the alcohol nature on adsorption, reactivity and selectivity.

\subsection{DRIFT spectra and photocatalytic oxidation of 4-pyridinylmethanol $\left(\mathrm{PyCH}_{2} \mathrm{OH}\right)$}

The characterization of surfaces with probe molecules that are also reactants is more appropriate if the goal is to investigate on the possible influence of acidic or basic properties on the photocatalytic activity [51]. The cases of benzyl alcohol and benzyl amine [52] might provide an example. We then decided to complement the results of Sect. 3.2 with those obtained using $\mathrm{PyCH}_{2} \mathrm{OH}$ as the starting substrate; this compound appeared to be a good candidate, because the lone electron pair of the $\mathrm{N}$ atom is expected to interact with LAS.

\subsubsection{DRIFT spectra}

Comparison of the data in Tables 1 and 2 shows that the amount of $\mathrm{PyCH}_{2} \mathrm{OH}$ adsorbed, for example, on PC105 and $\mathrm{N}-\mathrm{TiO}_{2}$, is higher by a factor of about 12 in comparison to analogous data for $\mathrm{PhCH}_{2} \mathrm{OH}$. The presence of different functionalities in this molecule causes the alcohol molecule to bind with several surface centres simultaneously [33].

This higher adsorption is in line with the presence of stronger LAS as determined from the FTIR spectra of adsorbed acetonitrile and pyridine (see previous Section).
Table 2 Adsorbed amount and visible light photocatalytic conversion of 4-pyridinylmethanol $\left(\mathrm{PyCH}_{2} \mathrm{OH}\right)$ to the corresponding aldehyde (PyCHO) on nitrogen-doped $\mathrm{TiO}_{2}\left(\mathrm{~N}-\mathrm{TiO}_{2}\right)$, undoped home-made $\mathrm{TiO}_{2}\left(\mathrm{U}-\mathrm{TiO}_{2}\right)$ and on commercial $\mathrm{TiO}_{2}$ specimen

\begin{tabular}{llll}
\hline $\mathrm{TiO}_{2}$ sample & $\begin{array}{l}\mathrm{BET} \text { area } \\
\left(\mathrm{m}^{2} \mathrm{~g}^{-1}\right)^{\mathrm{a}}\end{array}$ & $\begin{array}{l}\mathrm{PyCH}_{2} \mathrm{OH} \text { adsorbed } \\
\left(q_{\text {ads }}, \mu \mathrm{mol} \mathrm{m}^{-2}\right)^{\mathrm{b}}\end{array}$ & $\begin{array}{l}\mathrm{PyCHO} / \\
\mathrm{PyCH}_{2} \mathrm{OH}^{\mathrm{b}}\end{array}$ \\
\hline $\mathrm{N}-\mathrm{TiO}_{2}$ & 80 & 1.62 & 0.80 \\
$\mathrm{U}^{-\mathrm{TiO}_{2}}$ & 75 & 0.43 & 0.18 \\
$\mathrm{PC}_{205}$ & $85-95$ & 1.20 & 0.56 \\
$\mathrm{PC500}$ & 317 & 0.61 & 0.20 \\
\hline
\end{tabular}

${ }^{\mathrm{a}}$ This paper and Ref. [29]

${ }^{\mathrm{b}}$ Comparative experiments were carried out suspending a fixed amount of catalyst $\left(4 \mathrm{~g} \mathrm{~L}^{-1}\right)$ in a $\mathrm{CH}_{3} \mathrm{CN}$ solution containing $\mathrm{PyCH}_{2} \mathrm{OH}\left(1 \times 10^{-3} \mathrm{M}\right)$ followed by visible light irradiation $(\lambda>420 \mathrm{~nm})$. Adsorption in the dark and the effects of illumination were evaluated after a $1 \mathrm{~h}$ experiment. Quantitative analyses were carried out by gas chromatography (see Experimental Section). Reported values are the average of several repeated experiments. Errors never exceeded $\pm 5 \%$

Indeed, the FTIR spectra of $\mathrm{PyCH}_{2} \mathrm{OH}$ adsorbed on $\mathrm{N}^{-\mathrm{TiO}_{2}}$ or PC105 (Fig. 5S) presented a new band at $1445 \mathrm{~cm}^{-1}$ typical of the interaction of the pyridine moiety of $\mathrm{PyCH}_{2} \mathrm{OH}$ with LAS. In addition, the FTIR spectra of $\mathrm{PyCH}_{2} \mathrm{OH}$ adsorbed on both $\mathrm{N}-\mathrm{TiO}_{2}$ and $\mathrm{PC} 105$ featured a band at $\sim 1178 \mathrm{~cm}^{-1}$ (Fig. 5S). This band is assigned to the $\mathrm{C}-\mathrm{O}$ stretching mode of an adsorbed alcoholate and provides evidence of the stronger interaction of $\mathrm{PyCH}_{2} \mathrm{OH}$ with these two samples, in agreement with what reported above.

\subsubsection{Photocatalytic oxidation of $\mathrm{PyCH}_{2} \mathrm{OH}$}

Table 2 reports data concerning the formation of the aldehyde (PyCHO) under prolonged irradiation. In addition, for both the alcohols considered, $\mathrm{PhCH}_{2} \mathrm{OH}$ and $\mathrm{PyCH}_{2} \mathrm{OH}$, we evaluated reactivity as initial rates of aldehyde formation $\left(r^{\circ}\right)$ and quantum yields to minimize possible effects of alcohol-aldehyde adsorption competition (Table 3). An examination of $r^{\circ}$ versus $q_{\text {ads }}$ clearly reveals that, for the particular case of $\mathrm{PC} 105$, there is a striking photoactivity change upon changing the reactant alcohol.

As mentioned above, the results for $\mathrm{PhCH}_{2} \mathrm{OH}$ show that there is no apparent correlation between LAS and the photocatalytic activity of all the non-doped $\mathrm{TiO}_{2}$ samples investigated (Tables 1 and 3). In these cases, the $\mathrm{TiO}_{2}$ activity approximately increases with increasing surface area, both under steady-state and initial conditions. This seemingly confirms the mechanism proposed in the works by Higashimoto [10].

Conversely, the high reactivity of $\mathrm{PyCH}_{2} \mathrm{OH}$ on $\mathrm{PC} 105$ (Tables 2 and 3) cannot be explained by area effects. Since the number of LAS actually made available depends, among other factors, on the nature of the molecule to 
Table 3 Initial rates of aldehyde formation from $\mathrm{PhCH}_{2} \mathrm{OH}$ or $\mathrm{PyCH}_{2} \mathrm{OH}$ and corresponding quantum yields for $\mathrm{N}^{-\mathrm{TiO}_{2}}$ and various $\mathrm{TiO}_{2}$ samples under irradiation at $404-407 \mathrm{~nm}$

\begin{tabular}{|c|c|c|c|c|c|c|}
\hline \multirow[t]{2}{*}{ Sample } & \multicolumn{3}{|l|}{$\mathrm{PhCH}_{2} \mathrm{OH}$} & \multicolumn{3}{|c|}{$\mathrm{PyCH}_{2} \mathrm{OH}$} \\
\hline & $r^{\text {oa }}$ & $q_{\mathrm{ads}}^{\mathrm{b}}$ & $\varphi^{\mathrm{c}}$ & $\overline{r^{o a}}$ & $q_{\mathrm{ads}}^{\mathrm{b}}$ & $\varphi^{\mathrm{c}}$ \\
\hline $\mathrm{N}-\mathrm{TiO}_{2}$ & $8.3 \times 10^{-2}$ & 0.14 & $1.70 \times 10^{-2}$ & 0.73 & 1.62 & 0.150 \\
\hline U-TiO ${ }_{2}$ & $7.2 \times 10^{-3}$ & 0.11 & $1.45 \times 10^{-3}$ & 0.27 & 0.43 & 0.032 \\
\hline PC105 & $8.0 \times 10^{-3}$ & 0.10 & $1.63 \times 10^{-3}$ & 0.65 & 1.20 & 0.130 \\
\hline PC500 & $1.4 \times 10^{-2}$ & 0.16 & $2.80 \times 10^{-3}$ & 0.38 & 0.61 & 0.080 \\
\hline
\end{tabular}

${ }^{\mathrm{a}} r^{\circ}=$ initial rates $\left(\mu \mathrm{mol} \mathrm{m}{ }^{-2} \mathrm{~s}^{-1}\right)$

${ }^{\mathrm{b}} q_{\text {ads }}=$ amount of adsorbed alcohol $\left(\mu \mathrm{mol} \mathrm{m}{ }^{-2}\right)$ (Tables 1,2$)$

${ }^{\mathrm{c}} \varphi^{\circ}=$ quantum yield using initial rates (see Eq. 1). Initial rates were determined by gas chromatography (see Experimental section) be adsorbed [40], we conclude that the reactivity of $\mathrm{PyCH}_{2} \mathrm{OH}$ on $\mathrm{PC} 105$ is related to the reactant basicity that favours its interaction with LAS that are present in higher amount on this particular catalyst in comparison with the other undoped samples.

Peculiar characteristics of the surface/interface must, likewise, be the base of the high photocatalytic activity of $\mathrm{N}-\mathrm{TiO}_{2}$ in the selective oxidation of both $\mathrm{PhCH}_{2} \mathrm{OH}$ and $\mathrm{PyCH}_{2} \mathrm{OH}$; area effects and the number and strength of LAS alone are not sufficient to explain the behaviour of this catalyst. The nitrogen dopant introduces intra-bandgap energy levels and surface modifications [53] that are the possible reason of the Lewis acidity increase. In principle, we can envisage a specific interaction of alcohols with the dopant levels leading to a different oxidation mechanism on $\mathrm{N}^{-\mathrm{TiO}_{2}}$ compared with that on undoped $\mathrm{TiO}_{2}$ samples.

In regard to $\mathrm{N}_{-1 i O}$ selectivity, note that the $\mathrm{PyCHO} /$ $\mathrm{PyCH}_{2} \mathrm{OH}$ ratio decreases with respect to analogous results obtained with $\mathrm{PhCH}_{2} \mathrm{OH}$ (cfr. Tables 1 and 2), which might be surprising in view of $r^{\circ}$ and quantum yield parameters shown in Table 3. Under prolonged irradiation, it can be explained by a strong interaction of $\mathrm{PyCHO}$ with the surface that leads to a slow desorption, in turn, reasonably leading to its further transformation rather than accumulation.

Inspection of the FTIR spectrum for $\mathrm{N}-T i O_{2} / \mathrm{PyCH}_{2} \mathrm{OH}$ (Fig. 5S curve b) reveals a band at $\sim 1730 \mathrm{~cm}^{-1}$ that is attributed to the $\mathrm{C}=\mathrm{O}$ stretching mode of $\mathrm{PyCHO}$. In the absence of irradiation it is seemingly formed upon absorption of ambient light. To check that, we exposed a stirred suspension of $\mathrm{N}_{-} \mathrm{TiO}_{2}$ in $\mathrm{CH}_{3} \mathrm{CN}$ containing $\mathrm{PyCH}_{2} \mathrm{OH}\left(1 \times 10^{-3} \mathrm{M}\right)$ to laboratory ambient light and found that $78 \%$ of the initial $\mathrm{PyCH}_{2} \mathrm{OH}$ was converted selectively to $\mathrm{PyCHO}$ in $150 \mathrm{~min}$ (Fig. 6S). The reason why this system is so sensitive to visible light is assumed to be related to the interaction of both the pyridinyl nitrogen atom and the $-\mathrm{CH}_{2} \mathrm{OH}$ functional group with the surface. This increased interaction is favoured by the high amount of strong LAS on $\mathrm{N}-\mathrm{TiO}_{2}$ and on PC105, resulting in an increase of the concentration of surface species. The EPR investigation reported in the following section provides evidence for this interaction.

\subsection{Electron Paramagnetic Resonance Spectroscopy (EPR)}

EPR spectra could be observed at room temperature only for $\mathrm{N}^{-\mathrm{TiO}_{2}}$ (Fig. 4A, curve a) and not for any of the other undoped $\mathrm{TiO}_{2}$ samples. This particular spectrum is similar
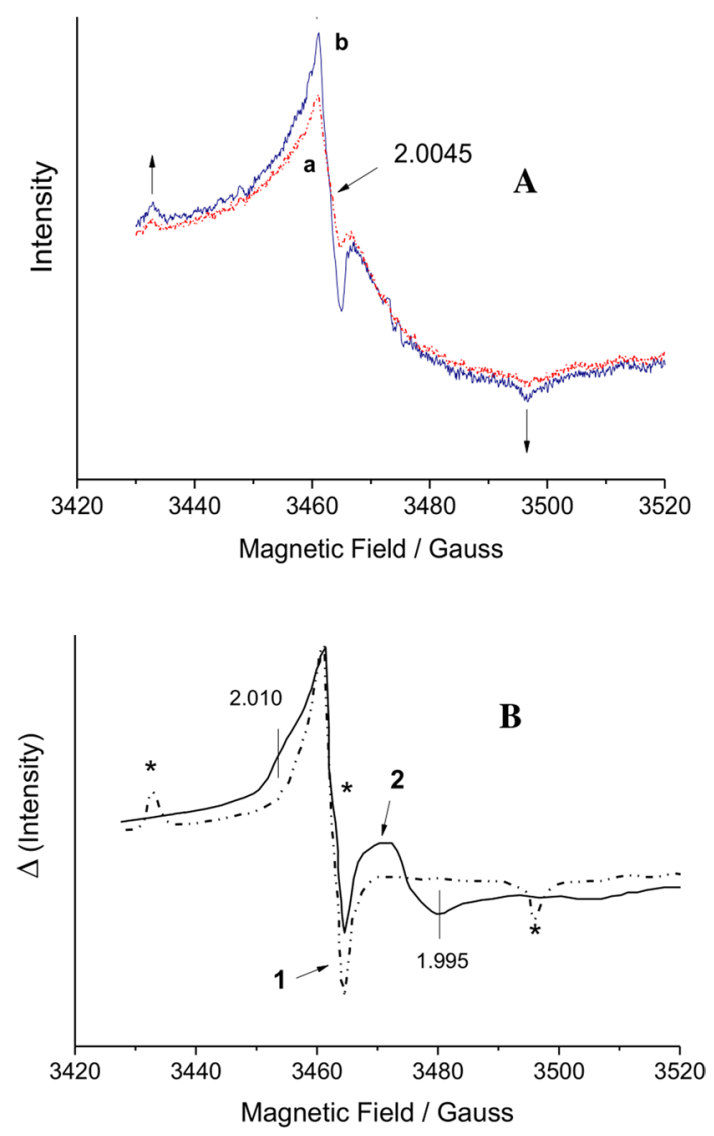

Fig. 4 A Room temperature EPR spectra of deaerated $\mathrm{N}-\mathrm{TiO}_{2}$ suspended in $\mathrm{CH}_{3} \mathrm{CN}$ in the dark (curve a, dotted line) and after irradiation $(\lambda>420)$ for 5 min (curve b, solid line). B Net EPR spectra (light-dark) in the absence (1) and in presence (2) of $\mathrm{PhCH}_{2} \mathrm{OH}$ $\left(2 \mathrm{mmol} \mathrm{L}^{-1}\right.$ in $\left.\mathrm{CH}_{3} \mathrm{CN}\right)$. The asterisks denote the triplet ascribed to paramagnetic nitrogen in $\mathrm{N}_{-} \mathrm{TiO}_{2}$ (see text) 


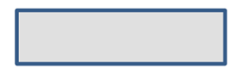

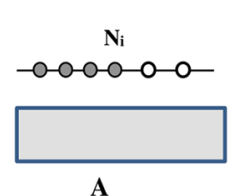

A

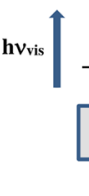

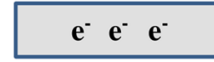

$\mathbf{e}^{-} \mathbf{e}^{-} \mathbf{e}^{-}$

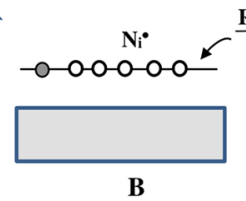

Scheme 1 Simplified illustration of the processes that we suggest may occur on $\mathrm{N}-\mathrm{TiO}_{2}$ in $\mathrm{CH}_{3} \mathrm{CN} / \mathrm{RCH}_{2} \mathrm{OH}$ under visible-light irradiation.

to those reported before at low temperature and discussed in previous literature $[18,54,55]$. However, broad the signal is, it is possible to observe a larger peak at $g=2.0045$ and weaker peaks at $g=2.022$ and $g=1.985$, each at a distance of $32 \mathrm{G}$ from the main one. This often-reported EPR triplet is seemingly a feature of nitrogen impurities in $\mathrm{TiO}_{2}[1,11$, 18], and corresponds to a paramagnetic species $\mathrm{N}_{\mathrm{i}}^{\bullet}$ from interstitial nitrogen $\left(\mathrm{N}_{\mathrm{i}}\right)$ chemically bound to a lattice [11, 56]. The $\mathrm{N}_{\mathrm{i}}$ localized energy state is located a few tenths of $\mathrm{eV}$ above the valence band [57] and is identified as the active centre of visible light photoactivity. Feng et al. [54, 55] described the active centre as $\mathrm{V}_{\mathrm{o}}{ }^{\bullet}$-NO-Ti to underline a role of vacancies $[56,57]$.

Under irradiation with visible light $(\lambda>420 \mathrm{~nm})$ of deaerated $\mathrm{N}-\mathrm{TiO}_{2}$ suspensions, the intensity of the EPR signal increases (Fig. 4A, curve b), as often reported (for example Refs. $[55,56,58])$. In particular, irradiation causes a significant increase in the formation of paramagnetic $\mathrm{N}_{\mathrm{i}}{ }^{\bullet}$ as clearly evident in the net spectrum (light-dark) of Fig. 4B (curve 1). This behaviour is attributed to visible-light excitation of electrons from the occupied $\mathrm{N}_{\mathrm{i}}$ bandgap level to the conduction band [58].

For analogous experiments in the presence of $\mathrm{PhCH}_{2} \mathrm{OH}$ as the oxidizable species (Fig. 4B, curve 2), the net spectrum shows no evidence of $\mathrm{N}_{\mathrm{i}}{ }^{\bullet}$ formation. This is apparently due to charge transfer from the adsorbed alcohol to holes created in the $\mathrm{N}_{\mathrm{i}}$ band gap level by visible-light irradiation (reaction 4). This, indeed, can explain the disappearance of the paramagnetic nitrogen centres and formation of an activated adsorbate (reaction 5). Overall, the process can then be written as:

$\mathrm{N}_{\mathrm{i}}+\mathrm{hn}_{\mathrm{vis}} \rightarrow \mathrm{N}_{\mathrm{i}}^{\bullet}+\mathrm{e}^{-}$

$\mathrm{N}_{\mathrm{i}}^{\bullet}+\left(\mathrm{PhCH}_{2} \mathrm{OH}\right)_{\mathrm{ads}} \rightarrow \mathrm{N}_{\mathrm{i}}+\left(\mathrm{PhCH}_{2} \mathrm{OH}\right)_{\mathrm{ads}}^{\bullet+}$

At the same time, the broad signal with $g \approx 1.99$ is not identified with firm certainty but falls in the range of $g$ values assigned to $\mathrm{Ti}^{3+}$ (trapped electrons) [55, 59, 60], seemingly indicating that, following reactions (3-4) in anaerobic conditions, accumulation of electrons occurs (Scheme 1).
In addition, the shoulder (at $g=2.010$ ), observed only in the presence of the alcohol (Fig. 4B, curve 2), might be tentatively explained by the formation of surface-stabilized alkoxy $\left(\mathrm{PhCH}_{2} \mathrm{O}^{\bullet}\right)$ radicals $[61,62]$.Kindly check Graphical abstract and Scheme 1 are identified correctly, as the images seems to be same.Scheme 1 is correct.The correct Graphical Abstract has been attached.

To sum up, we think that the EPR data provide important new evidence on the mechanism of photochemical processes occurring on $\mathrm{N}_{-} \mathrm{TiO}_{2}$ under visible-light irradiation. In the context of this predominant reaction mechanism, the role of the strong LAS on the surface of this catalyst would be to contribute to increase the concentration of the reacting species.

\section{Conclusions}

The selective oxidation of two structurally related alcohols, $\mathrm{PhCH}_{2} \mathrm{OH}$ and $\mathrm{PyCH}_{2} \mathrm{OH}$, to the corresponding aldehydes under visible-light irradiation, occurs with different efficiency and via different mechanisms on a home-prepared $\mathrm{N}-\mathrm{TiO}_{2}$ and on commercial undoped $\mathrm{TiO}_{2}$ samples.

FTIR spectra of adsorbed acetonitrile and pyridine have shown the presence of strong Lewis acid sites (LAS) on $\mathrm{N}-\mathrm{TiO}_{2}$ and on one of the undoped commercial samples (PC105). Nevertheless, the selective oxidation of $\mathrm{PhCH}_{2} \mathrm{OH}$ on all commercial materials does not depend on Lewis acidity but rather correlates with surface area. This correlation is consistent with a mechanism involving the adsorption of $\mathrm{PhCH}_{2} \mathrm{OH}$ on the surface and its interaction with $\mathrm{OH}$ surface groups leading to the formation of CT complexes between the alcohol and $\mathrm{TiO}_{2}$. The photoactivity of $\mathrm{N}-\mathrm{TiO}_{2}$ is comparatively higher and does not obey this trend.

In the oxidation of $\mathrm{PyCH}_{2} \mathrm{OH}$, the photoactivity of $\mathrm{PC} 105$ becomes close to that of $\mathrm{N}-\mathrm{TiO}_{2}$. This drastic change of reactivity compared to the analogous case of $\mathrm{PhCH}_{2} \mathrm{OH}$ can likely be ascribed to a contribution of strong LAS that respond to the Lewis basicity of this molecule.

Room temperature EPR investigations performed with $\mathrm{N}-\mathrm{TiO}_{2}$ suggests that nitrogen doping is responsible of intra band gap levels. Visible-light irradiation starts a new oxidation mechanism that involves a charge transfer from the adsorbed alcohol to holes photogenerated in the nitrogen dopant band gap level. As the amount of adsorbed reactant matters, the strong LAS of this catalyst plausibly increase the alcohol concentration on the surface.

Supplementary Information The online version contains supplementary material available at https://doi.org/10.1007/s43630-021-00137-4.

Acknowledgements We kindly acknowledge funding by University of Ferrara, FAR 2020. 


\section{Declarations}

Conflict of interest There are no conflicts to declare.

\section{References}

1. Etacheri, V., Di Valentin, C., Schneider, J., Bahnemann, D., \& Pillai, S. C. (2015). Visible-light activation of $\mathrm{TiO}_{2}$ photocatalysts: advances in theory and experiments. Journal of Photochemistry \& Photobiology C: Photochemistry Reviews, 25, 1-29.

2. Wang, Z., Chen, C., Ma, W., \& Zhao, J. (2013). Sensitization of titania semiconductor: a promising strategy to utilize visible light. In P. Pichat (Ed.), Photocatalysis and water purification: from fundamentals to recent applications (pp. 199-240). Wiley-VCH Verlag.

3. Liu, S., Guo, E., \& Yin, L. (2012). Tailored visible-light driven anatase $\mathrm{TiO}_{2}$ photocatalysts based on controllable metal ion doping and ordered mesoporous structure. Journal of Materials Chemistry, 22, 5031-5041.

4. Di Paola, A., Bellardita, M., Marcì, G., Palmisano, L., Parrino, F., \& Amadelli, R. (2011). Preparation of Sm-loaded brookite $\mathrm{TiO}_{2}$ photocatalysts. Catalysis Today, 161(1), 35-40.

5. Asahi, R., Morikawa, T., Irie, H., \& Ohwaki, T. (2014). Nitrogen-doped titanium dioxide as visible-light-sensitive photocatalyst: designs, developments, and prospects. Chemical Reviews, 114(19), 9824-9852.

6. Gomathi Devi, L., \& Kavitha, R. (2014). Review on modified $\mathrm{N}-\mathrm{TiO}_{2}$ for green energy applications under UV/visible light: selected results and reaction mechanisms. RSC Advances, 4, 28265-28299.

7. Marschall, R., \& Wang, L. (2014). Non-metal doping of transition metal oxides for visible-light photocatalysis. Catalysis Today, 225, 111-135.

8. Bakar, S. A., \& Ribeiro, C. (2016). Nitrogen-doped titanium dioxide: an overview of material design and dimensionality effect over modern applications. Journal of Photochemistry \& Photobiology C: Photochemistry Reviews, 27, 1-29.

9. Fang, W., Xing, M., \& Zhang, J. (2017). Modifications on reduced titanium dioxide photocatalysts: A review. Journal of Photochemistry \& Photobiology C: Photochemistry Reviews, 32, 21-39.

10. Higashimoto, S. (2019). Titanium-dioxide-based visible-lightsensitive photocatalysis: mechanistic insight and applications. Catalysts, 9(2), 201.

11. Chiesa, M., Livraghi, S., Paganini, M. C., Salvadori, E., \& Giamello, E. (2020). Nitrogen-doped semiconducting oxides. Implications on photochemical, photocatalytic and electronic properties derived from EPR spectroscopy. Chemical Science, 11, 6623-6641.

12. Zhang, G., Kim, G., \& Choi, W. (2014). Visible light driven photocatalysis mediated via ligand-to-metal charge transfer (LMCT): an alternative approach to solar activation of titania. Energy \& Environmental Science, 7, 954-966.

13. Amadelli, R., Samiolo, L., Maldotti, A., Molinari, A., Valigi, M., \& Gazzoli, D. (2008). Preparation, characterisation and photocatalytic behaviour of $\mathrm{Co}-\mathrm{TiO}_{2}$ with visible light response. International Journal of Photoenergy, 2008, 1-9.

14. Gavartin, L., Shluger, A. L., Foster, A. S., \& Bersuker, G. I. (2005). The role of nitrogen-related defects in high- dielectric oxides: density-functional studies. Journal of Applied Physics, 97(5), 13

15. Quesada-Cabrera, R., Sotelo-Vazquez, C., Darr, J. A., \& Parkin, I. P. (2014). Critical influence of surface nitrogen species on the activity of $\mathrm{N}$-doped $\mathrm{TiO}_{2}$ thin-films during photodegradation of stearic acid under UV light irradiation. Applied Catalysis B: Environmental, 160-161, 582-588.

16. Mrowetz, M., Balcerski, W., Colussi, A. J., \& Hoffmann, M. R. (2004). Oxidative power of nitrogen-doped $\mathrm{TiO}_{2}$ photocatalysts under visible illumination. Journal of Physical Chemistry B, 108(45), 17269-17273.

17. Ansari, S. A., Khan, M. M., Ansari, M. O., \& Cho, M. H. (2016). Nitrogen-doped titanium dioxide $\left(\mathrm{N}\right.$-doped $\left.\mathrm{TiO}_{2}\right)$ for visible light photocatalysis. New Journal of Chemistry, 40(4), 3000-3009.

18. Amadelli, R., Samiolo, L., Borsa, M., Bellardita, M., \& Palmisano, $\mathrm{L}$. (2013). $\mathrm{N}^{-} \mathrm{TiO}_{2}$ photocatalysts highly active under visible irradiation for $\mathrm{NO}_{\mathrm{X}}$ abatement and 2-propanol oxidation. Catalysis Today, 206, 19-25.

19. Shiraishi, Y., \& Hirai, T. (2008). Selective organic transformations on titanium oxide-based photocatalysts. Journal of Photochemistry \& Photobiology C: Photochemistry Reviews, 9(4), 157-170.

20. Molinari, A., Maldotti, A., \& Amadelli, R. (2013). Heterogeneous photocatalytic systems for partial and selective oxidation of alcohols and polyols. Current Organic Chemistry, 17(21), 2382-2405.

21. Dohnálek, Z., Lyubinetsky, I., \& Rousseau, R. (2010). Thermallydriven processes on rutile $\mathrm{TiO}_{2}(110)-(1 \times 1)$ : a direct view at the atomic scale. Progress in Surface Science, 85(5-8), 161-205.

22. Samiolo, L., Valigi, M., Gazzoli, D., \& Amadelli, R. (2010). Photo-electro catalytic oxidation of aromatic alcohols on visible light-absorbing nitrogen-doped $\mathrm{TiO}_{2}$. Electrochimica Acta, 55(26), 7788-7795.

23. Li, R., Kobayashi, H., Guo, J., \& Fan, J. (2011). Visible-light induced high-yielding benzyl alcohol-to-benzaldehyde transformation over mesoporous crystalline $\mathrm{TiO}_{2}$ : a self-adjustable photooxidation system with controllable hole-generation. Journal of Physical Chemistry C, 115(47), 23408-23416.

24. Martra, G. (2000). Lewis acid and base sites at the surface of microcrystalline $\mathrm{TiO}_{2}$ anatase: relationships between surface morphology and chemical behaviour. Applied Catalysis A: General, 200(1-2), 275-285.

25. Corma, A., \& García, H. (2002). Lewis acids as catalysts in oxidation reactions: From homogeneous to heterogeneous systems. Chemical Reviews, 102(10), 3837-3892.

26. Metiu, H., Chretien, S., Hu, Z., Li, B., \& Sun, X. (2012). Chemistry of Lewis acid-base pairs on oxide surfaces. Journal of Physical Chemistry C, 116(19), 10439-10450.

27. Liang, S., Wen, L., Lin, S., Bi, J., Feng, P., Fu, X., \& Wu, L. (2014). Monolayer $\mathrm{HNb}_{3} \mathrm{O}_{8}$ for selective photocatalytic oxidation of benzylic alcohols with visible light response. Angewandte Chemie International Edition, 53(11), 2951-2955.

28. Koito, Y., Rees, G. J., Hanna, J. V., Li, M. M. J., Peng, Y.-K., Puchtler, T., Taylor, R., Wang, T., Kobayashi, H., Teixeira, I. F., Khan, M. A., Kreissl, H. T., \& Edman Tsang, S. C. (2017). Structure-activity correlations for Brønsted acid, Lewis acid and photo- catalysed reactions of exfoliated crystalline niobium oxides. ChemCatChem, 9(1), 144-154.

29. Agrios, A. G., \& Pichat, P. (2006). Recombination rate of photogenerated charges versus surface area: opposing effects of $\mathrm{TiO}_{2}$ sintering temperature on photocatalytic removal of phenol, anisole, and pyridine in water. Journal of Photochemistry \& Photobiology A: Chemistry, 180(1-2), 130-135.

30. Ryu, J., \& Choi, W. (2008). Substrate-specific photocatalytic activities of $\mathrm{TiO}_{2}$ and multiactivity test for water treatment application. Environmental Science \& Technology, 42(1), 294-300.

31. Guerrini, E., \& Trasatti, S. (2006). Recent developments in understanding factors of electrocatalysis. Russian Journal of Electrochemistry, 42, 1017-1025.

32. Kislenko, S. A., Amirov, R. H., \& Samoylov, I. S. (2013). Effect of cations on the $\mathrm{TiO}_{2}$ /acetonitrile interface structure: a molecular dynamics study. Journal of Physical Chemistry C, 117(20), 10589-10596. 
33. Davydov, A. (2003). Molecular spectroscopy of oxide catalyst surfaces. John Wiley \& Sons Ltd Ed.

34. Araujo, Z., Mendive, C. B., Garcìa Rodenas, L. A., Morando, P. J., Regazzoni, A. E., Blesa, M. A., \& Bahnemann, D. (2005). FT-IRATR as a tool to probe photocatalytic interfaces. Colloids and Surfaces A: Physicochemical and Engineering Aspects, 265(1-3), 73-80.

35. Primet, M., Pichat, P., \& Mathieu, M.-V. (1971). Infrared study of the surface of titanium dioxides. I. Hydroxyl groups. Journal of Physical Chemistry, 75, 1216-1220.

36. Erdem, B., Hunsicker, R. R. A., Simmons, G. W., Sudol, E. D., Dimonie, V. L., \& El-Aasser, M. S. (2001). XPS and FTIR surface characterization of $\mathrm{TiO}_{2}$ particles used in polymer encapsulation. Langmuir, 17(9), 2664-2669.

37. Szczepankiewicz, S. H., Colussi, A. J., \& Hoffmann, M. R. (2000). Infrared spectra of photoinduced species on hydroxylated titania surfaces. Journal of Physical Chemistry B, 104(42), 9842-9850.

38. Zhuang, J., Rusu, C. N., \& Yates, J. T., Jr. (1999). Adsorption and photooxidation of $\mathrm{CH}_{3} \mathrm{CN}$ on $\mathrm{TiO}_{2}$. Journal of Physical Chemistry $B, 103(33), 6957-6967$.

39. Raskó, J., \& Kiss, J. (2006). Adsorption and catalytic reactions of acetonitrile and acetonitrile-oxygen mixture on $\mathrm{TiO}_{2}$-supported rhodium catalysts. Applied Catalysis A: General, 303(1), 56-61.

40. Busca, G. (1999). The surface acidity of solid oxides and its characterization by IR spectroscopic methods. An attempt at systematization. Physical Chemistry Chemical Physics, 1(5), 723-736.

41. Pichat, P., Mathieu, M.-V., \& Imelik, B. (1969). Étude par spectrométrie infrarouge de l'adsorption de la pyridine et de la pyridine deutériée sur une silice amorphe, une alumine et un catalyseur silice-alumine. Bulletin de la Sociétè Chimique de France, 8 , 2611.

42. Bezrodna, T., Puchkovska, G., Shimanovska, V., Chashechnikova, I., Khalyavka, T., \& Baran, J. (2003). Pyridine-TiO 2 surface interaction as a probe for surface active centers analysis. Applied Surface Science, 214(1-4), 222-231.

43. Héroguel, F., Silvioli, L., Du, Y.-P., \& Luterbacher, J. S. (2018). Controlled deposition of titanium oxide overcoats by non-hydrolytic sol gel for improved catalyst selectivity and stability. Journal of Catalysis, 358, 50-61.

44. Barzetti, T., Selli, E., Moscotti, D., \& Forni, L. (1996). Pyridine and ammonia as probes for FTIR analysis of solid acid catalysts. Journal of the Chemical Society, Faraday Transactions, 92(8), 1401-1407.

45. Myers, T. L., Brauer, C. S., Su, Y.-F., Blake, T. A., Tonkyn, R. G., Ertel, A. B., Johnson, T. J., \& Richardson, R. L. (2015). Quantitative reflectance spectra of solid powders as a function of particle size. Applied Optics, 54(15), 4863-4875.

46. Mino, L., Negri, C., Santalucia, R., Cerrato, G., Spoto, G., \& Martra, G. (2020). Morphology, surface structure and water adsorption properties of $\mathrm{TiO}_{2}$ nanoparticles: a comparison of different commercial samples. Molecules, 25(20), 4605.

47. Kim, Y. K., Kay, B. D., White, J. M., \& Dohnalek, Z. (2007). Alcohol chemistry on rutile $\mathrm{TiO}_{2}(110)$ : The influence of alkyl substituents on reactivity and selectivity. The Journal of Physical Chemistry C, 111(49), 18236-18242.

48. Li, C.-J., Xu, G.-R., Zhang, B., \& Gong, J. R. (2012). High selectivity in visible-light-driven partial photocatalytic oxidation of benzyl alcohol into benzaldehyde over single-crystalline rutile
$\mathrm{TiO}_{2}$ nanorods. Applied Catalysis B: Environmental, 115-116, 201-208.

49. Zhao, L., Gu, F. L., Kim, M., \& Zhang, R.-Q. (2017). DFT study of benzyl alcohol/ $/ \mathrm{TiO}_{2}$ interfacial surface complex: Reaction pathway and mechanism of visible light absorption. Journal of Molecular Modeling, 23, 285.

50. Fridman, V. Z., Davydov, A. A., \& Titievsky, K. (2004). Dehydrogenation of cyclohexanol on copper-containing catalysts: II. The pathways of the cyclohexanol dehydrogenation reaction to cyclohexanone on copper-active sites in oxidation state $\mathrm{Cu} 0$ and $\mathrm{Cu}+$. Journal of Catalysis, 222(2), 545-557.

51. Lercher, J. A., Gründling, C., \& Eder-Mirth, G. (1996). Infrared studies of the surface acidity of oxides and zeolites using adsorbed probe molecules. Catalysis Today, 27(3-4), 353-376.

52. Higashimoto, S., Hatada, Y., Ishikawa, R., Azuma, M., Sakata, Y., \& Kobayashi, H. (2013). Selective photocatalytic oxidation of benzyl amine by $\mathrm{O}_{2}$ into $\mathrm{N}$-benzylidenebenzylamine on $\mathrm{TiO}_{2}$ using visible light. Current Organic Chemistry, 17(21), 2374-2381.

53. Batzill, M., Morales, E. H., \& Diebold, U. (2006). Influence of nitrogen doping on the defect formation and surface properties of $\mathrm{TiO}_{2}$ rutile and anatase. Physical Review Letters, 96(2), 026103.

54. Feng, C., Jin, Z., Zhang, J., Wu, Z., \& Zhang, Z. (2010). Coaction of sub-band and doped nitrogen on visible light photoactivity of $\mathrm{N}$-doped $\mathrm{TiO}_{2}$. Photochemistry and Photobiology, 86(6), 1222-1229.

55. Feng, C., Wang, Y., Jin, Z., Zhang, J., Zhang, S., Wu, Z., \& Zhang, Z. (2008). Photoactive centers responsible for visible-light photoactivity of N-doped $\mathrm{TiO}_{2}$. New Journal of Chemistry, 32(6), 1038-1047.

56. Foo, C., Li, Y., Lebedev, K., Chen, T., Day, S., Tang, C., \& Tsang, S. C. E. (2021). Characterisation of oxygen defects and nitrogen impurities in $\mathrm{TiO}_{2}$ photocatalysts using variable-temperature $\mathrm{X}$-ray powder diffraction. Nature Communications, 12, 1.

57. Emeline, A., Kuznetsov, V. N., Rybchuk, V. K., \& Serpone, N. (2008). Visible-light-active titania photocatalysts: the case of $\mathrm{N}$-doped $\mathrm{TiO}_{2} \mathrm{~s}$-properties and some fundamental issues. International Journal of Photoenergy, 2008, 1.

58. Finazzi, E., Di Valentin, C., Selloni, A., \& Pacchioni, G. (2007). First principles study of nitrogen doping at the anatase $\mathrm{TiO}_{2}(101)$ surface. The Journal of Physical Chemistry C, 111(26), 9275-9282.

59. Barolo, G., Livraghi, S., Chiesa, M., Paganini, M. C., \& Giamello, E. (2012). Mechanism of the photoactivity under visible light of $\mathrm{N}$-doped titanium dioxide. Charge carriers migration in irradiated $\mathrm{N}-\mathrm{TiO} 2$ investigated by electron paramagnetic resonance. The Journal of Physical Chemistry C, 116(39), 20887-20894.

60. Xiong, L.-B., Li, J.-L., Yang, B., \& Yu, Y. (2012). Ti ${ }^{3+}$ in the surface of titanium dioxide: generation, properties and photocatalytic application. Journal of Nanomaterials, 2012, 13.

61. Kumar, C. P., Gopal, N. O., Wang, T. C., Wong, M.-S., \& Ke, S. C. (2006). EPR investigation of $\mathrm{TiO}_{2}$ nanoparticles with temperature-dependent properties. The Journal of Physical Chemistry B, $110(11), 5223-5229$.

62. Malakhova, I. V., Ermolaev, V. K., \& Paukshtis, E. A. (2000). The radicals generation in the methanol oxidation on a Pt-containing catalysts. Influence of support acidic properties. Journal of Molecular Catalysis A: Chemical, 158(1), 439-442. 